\title{
Stress and Well-Being of University Staff: An Investigation Using the Demands-Resources- Individual Effects (DRIVE) Model and Well-Being Process Questionnaire (WPQ)
}

\author{
Gary Williams, Kai Thomas, Andrew P. Smith* \\ Centre for Occupational and Health Psychology, School of Psychology, Cardiff University, Cardiff, UK \\ Email: *smithap@cardiff.ac.uk
}

How to cite this paper: Williams, G., Thomas, K., \& Smith, A. P. (2017). Stress and Well-Being of University Staff: An Investigation Using the Demands-Resources-Individual Effects (DRIVE) Model and Well-Being Process Questionnaire (WPQ). Psychology, 8, 1919-1940.

https://doi.org/10.4236/psych.2017.812124

Received: August 23, 2017

Accepted: October 13, 2017

Published: October 16, 2017

Copyright $\odot 2017$ by authors and Scientific Research Publishing Inc. This work is licensed under the Creative Commons Attribution International License (CC BY 4.0).

http://creativecommons.org/licenses/by/4.0/

\begin{abstract}
Research suggests that university staff have high stress levels but less is known about the well-being of this group. The present study used an adapted version of the Demands-Resources-Individual Effects (DRIVE) model to investigate these topics. It also used the Well-Being Process Questionnaire (WPQ) which consists of single items derived from longer scales. One hundred and twenty university staff participated in an online survey. The single items had good concurrent validity and estimated reliability. Factor analyses showed that single items and the longer scales loaded on the same factor. Work characteristics could be sub-divided into two factors (resources and demands), as could personality (positive personality and openness/agreeable/conscientious), coping (positive and negative coping) and outcomes (positive well-being and negative outcomes such as stress and anxiety). Results from regressions showed that positive well-being was predicted by positive personality and positive coping. Negative outcomes were predicted by job demands and negative coping. Overall, the study has demonstrated the utility of the adapted DRIVE model and shown that a short single item measuring instrument can quickly capture a wide range of job and psychosocial characteristics.
\end{abstract}

\section{Keywords}

DRIVE Model, WPQ, Wellbeing, University Staff

\section{Introduction}

The aim of the present study was to investigate stress and well-being in university staff using the Demands-Resources-Individual Effects (DRIVE) model 
(Mark \& Smith, 2008) and a measuring instrument using short versions of established questionnaires (the Wellbeing Process Questionnaire-WPQ Short Form, Williams \& Smith, 2012). The DRIVE model considers both work characteristics and individual effects. It has largely been used to study negative outcomes but is adapted here to also investigate positive wellbeing. As more variables are included in a survey the length of it increases and this leads to reduced compliance from participants. The WPQ consists of single items measuring the same concepts as longer scales. Previous research has established the validity of this approach which is here applied to investigate the wellbeing of university staff. The next section briefly reviews stress and well-being of university staff.

\subsection{Stress and Well-Being of University Staff}

Research (e.g. Winefield \& Jarrett, 2001; Kinman, 2001; 2008) suggests that stress levels in academic institutions are high and that stress has increased significantly over the last 20 years. This may reflect the persistent demands of academic life (Singh \& Bush, 1998) and the large number of competing roles, such as teaching, research, seeking funding, writing papers, and meeting seminar and tutorial commitments (Abouserie, 1996). The stress may also be attributed to falling salaries and increasing workloads (Fisher, 1994). A study from 20 years ago (Abouserie, 1996 ) found that $74 \%$ of staff were moderately stressed, and nearly $15 \%$ were extremely stressed, with lecturers the most negatively affected, followed by research assistants and professors. Another study (Gillespie, Walsh, Winefield, Dua, \& Stough, 2001), citing Association of University Teachers (AUT) figures from 1990, stated that $49 \%$ of UK university employees had stressful jobs. An AUT study in 2003 (cited by Tytherleigh, Webb, Cooper, \& Ricketts, 2005) found that $93 \%$ of AUT members had suffered work related stress, with high levels of dissatisfaction with pay and workload. This research (Gillespie et al., 2001) identified several key factors that are commonly associated with stress in academic staff. These included work overload, time pressure, lack of prospects, poor levels of reward and recognition, fluctuating roles, poor management, poor resources and funding, and student interactions. Other stressors identified from the literature included high expectations, lack of security, lack of communication, inequality, and lack of feedback. A more recent study (Kinman \& Court, 2010) investigated the levels of job-related stressors (job demands, control, social support, interpersonal relationships, role clarity, and involvement in organizational change) in a sample of 9740 academic employees at higher-education institutions in the UK. They found that all except one (control) exceeded the safe benchmarks recommended by the Health and Safety Executive.

Another study (Winefield \& Jarrett, 2001) found that in a sample of over 2000 Australian university staff, $43.7 \%$ were classified as clinical cases on the General Health Questionnaire, suggesting high levels of anxiety and depression. This confirms the results of two earlier studies, (Sharpley, Reynolds, Acosta, \& Dua, 1996) the first of which found that stress was a significant problem for $25 \%$ of 
staff, with reports of increased anxiety, absence, injuries, illnesses, and poorer physical health, and the second (Blix, Cruise, Mitchell, \& Blix, 1994) found that $48 \%$ of staff reported some health problems resulting from work stress. More recent research (Tytherleigh et al., 2007) found evidence that university staff exhibited significantly less organizational commitment compared to other private and public sector workers, as well as being more stressed by lack of control and resources, and worries about low pay and benefits.

Stress in university staff does not just have an impact on the employees themselves, but can have serious consequences for students as well (Lease, 1999). Indeed, one study (Blix et al., 1994) found that $84 \%$ of their sample of 400 university staff reported that their productivity at work had been negatively affected by stress and 33\% felt it suffered at least 50\% of the time. Boyd and Wylie (cited in Gillespie et al., 2001) found that workload and stress resulted in less time spent on research, publishing, and development, and lower teaching standards, as well as having negative effects on staff relationships, and emotional health, family relationships, and leisure activities. Other research (Blix et al., 1994) has shown that job stress significantly increased the likelihood of staff intending to leave academia. Bowen and Schuster (cited in Gillespie et al., 2001) also reported that stress had a negative impact on staff morale, and many of the interviewed academics were angry, embittered and felt devalued and abandoned.

Mark and Smith (2012) investigated the relationships between job demands, control, social support, efforts, rewards, coping, and attributional style, in predicting anxiety, depression, and job satisfaction in a sample of 307 university employees from the UK. Results were compared to those from a sample of 120 members of the general population. Workplace demands, intrinsic and extrinsic effort, and negative coping and attributional behaviors were associated with high levels of depression and anxiety, and lower job satisfaction in the university employees. Rewards, social support, job control, and positive coping and attributional behaviors were associated with lower levels of depression and anxiety, and high job satisfaction. The study was important in that it added to the growing research on university samples by showing that a transactional approach should be adopted.

The above literature review also shows that there have been few studies of positive outcomes (life satisfaction; positive affect; happiness) in university staff. Another aim of the present study was to provide information on this topic.

\subsection{The Demands-Resources-Individual Effects Model}

Mark \& Smith (2008) suggest that an ideal approach would be to have a model of the stress process that accounts for circumstances, individual experiences, and subjective perceptions without too much complexity. Their proposed basic model included factors from the Demands-Control-Support (DCS) model (Johnson \& Hall, 1988), the Effort-Reward-Imbalance (ERI) model (Siegrist, 1996), coping behaviours (Folkman \& Lazarus, 1980), and attributional expla- 
natory styles (Peterson, 1991) as well as outcomes including anxiety, depression, and job satisfaction. These variables were categorized as work demands, work resources (e.g. control, support), individual differences (e.g. coping style, attributional style), and outcomes, although the model was intended as a framework into which any relevant variables can be applied. This simple model proposed direct effects on outcomes from the other variable groups, as well as a moderating effect of individual differences and resources on demands.

A more complex version (the enhanced DRIVE model) was also developed to acknowledge a subjective element and included perceived stress as well as further interactive effects. Research using the DRIVE model has supported the direct effects of these variable groups on outcomes, although little support was found for interactions (Mark \& Smith, 2012a; 2012b). Stronger support of direct effects compared to interactions has also been found in research on other models such as the DCS model, where a review has shown that there was less evidence for the buffering effect of control and support than the direct effects of these variables on outcomes (Van Der Doef \& Maes, 1999).

The DRIVE model includes multiple factors such as circumstances and individual differences, which can be applied simply in terms of direct relationships and cumulative effects, and can also be easily adapted by adding or removing factors relevant to the circumstances they are applied to. In the present study, the model now included personality measures, as it has been suggested that personality is a significant predictor of emotional well-being (Diener et al., 2003; Costa \& McCrae, 1980; Dolan, Peasgood, \& White, 2008) and that taking into account personality is important for increasing well-being (Diener, 2000).

The model used here also included subjective well-being (SWB) more directly, with satisfaction, positive affect and happiness as separate components as recommended by prior research (Diener, Suh, Lucas, \& Smith, 1999). The other outcomes were stress, depression, and anxiety as they are the most commonly assessed negative aspects of well-being. While these outcomes are measured individually, they can also be conceptually grouped in terms of positive, negative, cognitive (appraisals), and emotional categories, and more broadly as aspects of well-being as a whole. As a result, the present application provides a simpler but broader approach to well-being than the original DRIVE model, although an increased potential for redundant variables is acknowledged.

\subsection{Development of Single-Item Measures of Well-Being and Associated Variables}

Items were created for variables associated with well-being in terms of the DRIVE model. The model assumes direct relationships between work demands, work resources, individual differences, personality, and outcomes. Items were created in order to explore a range of variables for each variable group, as past research has demonstrated that multiple associated variables can contribute uniquely to well-being outcomes and that these contributions may vary depending on the specific well-being outcome involved. At the same time, as suggested by 
Smith et al. (2009), it is not possible to measure every possibly important variable and therefore the variables were chosen to assess single-item measures of a broad range of variables associated with well-being while also balancing this with a realistic selection of the vast number of variables and measures developed over the years. The variables that were chosen represent those that were used in previous research using a multi-faceted approach to workplace well-being (e.g. Mark \& Smith, 201a; 2012b; Smith et al., 2004; Smith et al., 2000), were congruent with international and national well-being definitions (Waldron, 2010; Wismar et al., 2013), and had strong research evidence for their association with well-being (e.g. Diener et al., 1999; DeNeve \& Cooper, 1998; Diener et al., 2003; Tsutsumi \& Kawakami, 2004; Van Der Doef \& Maes, 1999) and their recommendation for well-being assessment (e.g. Rick et al., 2001; Parkinson, 2007).

\section{DRIVE Model Variables}

As the DRIVE model is used as the theoretical framework of the research, the original variables used in previous research using this framework were also included (Mark \& Smith, 2012a; 2012b). This involved the use of demands and effort as the work characteristics making up the demands variable group, reward, control, and support as the work characteristics making up the resources variable group, and coping style and attributional style making up the individual differences group. Additional variables were included because other factors fit into this framework and add to a multi-dimensional approach. The use of single-item measures enables their addition without a significant impact on survey length or response burden.

Work characteristics: The HSE Management Standards represent the current recommended method of measuring well-being psychosocial hazards in the workplace (Black, 2008), other variables not already accounted for by the DCS and ERI models were included. These variables were role understanding, supervisor relationship and consultation on change, which contributed to the resources group. Bullying has been identified as an important risk factor, particularly in nurses (Quine, 1999), and was also included as a demand. Measures of these variables were combined with those described above to represent context-relevant circumstances.

Personality: While individual differences have been accounted for previously in the DRIVE model by including coping style and attributional style variables, personality variables represent a significant omission in this area, particularly when considering subjective well-being outcomes where personality has been cited as potentially the most important predictor (Diener et al., 2003). The most commonly used model of personality is the five factor, or "Big 5" model (Steel et al., 2008) and extraversion and neuroticism in particular have demonstrated significant relationships with positive and negative well-being outcomes, although specific associations with other big 5 variables have also been demonstrated (Hayes \& Joseph, 2003). Extraversion, emotional stability, conscientiousness, agreeableness, and openness were therefore included. 
While these broad personality characteristics are the most frequently measured, it has also been stated that this may be an oversimplification of the associations between personality and well-being (Diener et al., 2003) and may lead to a loss of predictive variance from more specific personality variables (Schimmack et al., 2004). Other frequently cited variables associated with personality and well-being are optimism, self-esteem, and self-efficacy. Optimism has been associated with a range of well-being outcomes, including life satisfaction and happiness (Sharpe, Martin, \& Roth, 2011; Scheier, Carver, \& Bridges, 1994; Kluemper, Little, \& DeGroot, 2009) and others (Bandura, 1988) suggest that perceived self-inefficacy is the major source of anxiety and cause of avoidant behavior. Loss of self-esteem is an important variable in depression, negative affect and stress (Lee-Flynn et al., 2011). Each have also been suggested as potential buffers against negative well-being outcomes (Lee-Flynn et al., 2011; Chang et al., 2011; Maciejewski, Prigerson, \& Mazure, 2000) and have been implicated in research on the well-being of teachers (Schwarzer \& Hallum, 2008) and nurses (Chang et al., 2011). Measures of optimism, self-efficacy, and self-esteem have also been supported in reviews of well-being measures (Parkinson, 2007). In their review of personality variables and their associations with well-being, DeNeve and Cooper (1998) conclude that the most important personality variables appear to be those that are concerned with making healthy attributions. Although not specifically mentioned in their review, self-esteem, optimism, and self-efficacy can theoretically be said to represent positive attributions related to one's self, one's future, and one's abilities respectively. Optimism, self-esteem, and self-efficacy measures were therefore also included.

Outcomes: Outcomes were included primarily to acknowledge the well-being variables implicated in policy (Knapp et al., 2006; McDaid; Waldron, 2010; Wismar et al., 2013) and previous well-being research (e.g. Smith et al., 2004; Mark \& Smith, 2012a; Smith et al., 2009). Stress, depression, and anxiety were included as the nationally monitored negative psychological well-being outcomes (e.g. in the Labour Force Survey) and frequently assessed well-being outcomes in the workplace (e.g. Smith et al., 2009). In order to assess subjective wellbeing (SWB), positive mood, negative mood, and life satisfaction were also included. SWB has been demonstrated as distinct from mental health outcomes such as depression and anxiety (Headey \& Wearing, 1989; Keyes, 2006) and may be useful as an outcome for those who may not recognise depression in themselves or may not want to report it (Gargiulo \& Stokes, 2009). Furthermore, the subjective element of well-being and satisfaction judgements have been suggested as integral parts of a holistic concept of well-being (Diener et al., 1998; Waldron, 2010), satisfaction overall and with specific domains were referred to as appraisals. In the present research these elements are referred to as cognitive well-being in line with SWB theory (Diener, 1984).

Potential for redundancy. While the inclusion of further variables may increase predictive validity and account for the multi-dimensional nature of 
well-being, there is also the potential for increased redundancy. While these variables have each been associated with well-being, there is also discussion as to whether they each form independent relationships or simply act through associations with other important variables. Optimism, for example, may have associations with well-being through its impact on coping or explanatory style, with optimists more likely to use problem focused coping than emotional coping methods and more likely to have internal attributions for positive events (Kluemper et al., 2009; Scheier et al., 1994). Self-esteem may also be linked to optimism as a positive expectation regarding one's self-worth (Scheier et al., 1994) and each of these elements have also been suggested to be potentially just elements of broader personality constructs such as extraversion and neuroticism (Sharpe et al., 2011; Scheier et al., 1994) and therefore including both may be unnecessary. However it is also suggested that such variables contain a significant amount of unique variance and are worth exploring separately (Scheier et al., 1994) as it is not fully established whether such factors have unique associations beyond those accounted for by, for example, broad personality characteristics (Diener et al., 2003) or whether some measures may simply be assessing the same predictive variance in outcomes (Judge, Erez, Bono, \& Thoresen, 2002). Similarly, outcome variables such as satisfaction with life, depression, negative affect and anxiety have shown correlations between 0.31 and 0.72 in various reports but have also been concluded to have some degree of unique variance (Larsen, Diener, \& Emmons, 1985; Pavot \& Diener, 1993). While there is some potential for redundancy in the items therefore, the evidence regarding which variables are and are not relevant for well-being assessment is not conclusive. Single-item measures were created to assess this range of variables as part of an approach that was designed to assess the potential limitations of single-item measures in terms of the types of variables they may be suitable for and to provide more direct evidence of potential redundancy in this context by including variables together.

\subsection{Aims of the Study}

In summary, this research involved university staff and it has been shown that education professionals represent 1 out of 3 occupations with the highest estimated prevalence of work-related stress in the UK (HSE, 2013). Previous work on the DRIVE model also used a university staff sample (Mark \& Smith, 2012a) and therefore the application of this approach in this sample is already established, providing a suitable foundation for further research using the WPQ. There is a much smaller literature on positive well-being in university staff. Most studies of this topic have looked at job satisfaction and considered factors that alter it (Bentley et al., 2013). Quite often factors which improve job satisfaction (e.g. rewards, social support, control, positive coping and attributions) also lead to a reduction in negative outcomes (e.g. anxiety and depression, Mark \& Smith, 2012a). Other research (Winefield et al., 2014) has examined work-family con- 
flict and reduced well-being and has shown that there are two pathways through which management policies may improve well-being and productivity: improving job autonomy has direct effects on well-being whereas reducing job demands improves well-being by reducing work-family conflict. Overall, this review suggests that there is a need to provide more information on the predictors of positive well-being of university staff.

\section{Method}

This research was approved by the Ethics committee, School of Psychology, Cardiff University, and carried out with the informed consent of the participants. It involved an online survey presented using Survey Tracker which they could complete in their own time. The questionnaire was expected to take approximately one hour to complete. Participants were instructed that they could skip any questions that they were not comfortable answering, although all data were provided anonymously. Informed consent was achieved within the questionnaire where participants could not continue beyond the consent page without agreeing. Following the consent page participants were presented with an instructions sheet and following the questionnaire a debrief sheet was provided.

\subsection{Participants}

One hundred and twenty university staff members aged 20 - 64 participated in the study. This number of participants was considered satisfactory to identify the large effect sizes based on previous research, and to provide a meaningful cases-to-IV ratio for multiple regression analysis (Tabachnick \& Fidell, 2007). Participants from all areas of the university were able to participate, including finance, teaching, accommodation, and security, although the role of specific respondents was not recorded. The majority were aged 30 - 39 (32\%), married or living with a partner (63\%) and were educated to degree or higher degree level (73\%). Working patterns were most commonly full-time (81\%) fixed hours (79\%). This sample was considered representative of a typical UK university.

\subsection{Materials}

A questionnaire consisting of single-item measures, developed in-house, and established multi-item scales of the same measures was used. The variables measured and the associated multi-item scale are provided in Table 1 below. Multi-item comparisons were chosen based on their previous use in research and/or their recommendation in papers regarding well-being measurement (Parkinson, 2007; Rick et al., 2001). Where possible, the brief versions of measures were used to provide a fair representation of the number of items required in practical well-being assessment.

\subsection{Single-Item Measure Development}

The newly developed single-item measures were designed based on guidance from 
Table 1. The multi-item scales used in the current study.

\begin{tabular}{|c|c|c|c|}
\hline \multirow[t]{2}{*}{ Variable } & \multicolumn{2}{|c|}{ Number of items } & \multirow[t]{2}{*}{ Multi-item measure } \\
\hline & Multi & Single & \\
\hline Work characteristics & 16 & 3 & DCSQ (Sanne et al., 2005) \\
\hline Demands, control, and support & 32 & 2 & ERI Questionnaire (Siegrist et al., 2004) \\
\hline Effort and reward & 7 & 1 & LMX (Scandura \& Graen, 1984) \\
\hline Supervisor relationship & 8 & 2 & \\
\hline $\begin{array}{l}\text { Understanding of role and consultation on } \\
\text { change }\end{array}$ & 19 & 1 & HSE MS (HSE, 2004) \\
\hline \multicolumn{4}{|l|}{ Bullying } \\
\hline Personality & & & Quine (Quine, 1999) \\
\hline \multicolumn{4}{|l|}{ Extraversion, } \\
\hline Emotional stability, & 40 & 5 & \\
\hline $\begin{array}{c}\text { Conscientiousness, agreeableness, and } \\
\text { openness }\end{array}$ & 10 & 1 & Mini Markers (Saucier, 1994) \\
\hline Perceived self-esteem & 10 & 1 & \\
\hline Perceived self-efficacy & 10 & 1 & \\
\hline Optimism/pessimism & & & Rosenberg Self Esteem Scale (Rosenberg, 1965) \\
\hline Coping style & & & Generalized Self Efficacy Scale (Schwarzer \& Jerusalem, 1995) \\
\hline \multicolumn{4}{|l|}{ Problem-focused } \\
\hline Seeks social support & & & Life Orientation Test Revised (Scheier et al., 1994) \\
\hline \multicolumn{4}{|l|}{ Avoidance } \\
\hline Blame Self & 43 & 2 & \\
\hline Wishful thinking & & & $\begin{array}{l}\text { Ways of Coping Checklist Revised (Vitaliano, Russo, Carr, Maiuro, \& } \\
\text { Becker, 1985) }\end{array}$ \\
\hline \multicolumn{4}{|l|}{ Outcome measures } \\
\hline Depression & 7 & 1 & Hospital Anxiety and Depression Scale \\
\hline Anxiety & 7 & 1 & (Zigmond \& Snaith, 1983) \\
\hline Positive affect and negative affect & 10 & 2 & $\begin{array}{l}\text { Positive Affect and Negative Affect Schedule International Short Form } \\
\text { (Thompson, 2007) }\end{array}$ \\
\hline Life satisfaction & 5 & 1 & Satisfaction With Life Scale (Diener et al., 1985) \\
\hline Stress & 10 & 1 & Perceived Stress Scale 10 (Cohen \& Williamson, 1988) \\
\hline Total & 270 & 31 & \\
\hline
\end{tabular}

single-item measure development in the literature regarding uni-dimensionality and clarity for the respondent (Sackett \& Larson, 1990). The validity of a single-item measure may depend on how accurately the respondent understands the targeted construct. This meant that single-item measures included an initial statement or question and were followed by examples of what the item was referring to. An example in the case of optimism is given below. These examples within the item were statements taken from the multi-item measure in order to provide guidance on what the statement was referring to and maintain congru- 
ence between the single and multi-item responses.

"In general, I feel optimistic about the future (For example: I usually expect the best; I expect more good things to happen to me than bad; It's easy for me to relax) Disagree strongly 12345678910 Agree strongly."

Items that were structured in the form of an initial statement each had the response scale from "Disagree strongly" to "Agree strongly" while those with an initial question (e.g. "On a scale of one to ten, how depressed would you say you are in general?") each had the response scale from "Not at all" to "Extremely". All items had a response scale from 1 - 10, chosen for practical and statistical reasons. In terms of practicality, a consistent simple 1 - 10 scale is in line with the intended purpose of the items for a practical well-being measure. In statistical terms, a 1 - 10 scale allows a greater range of potential responses than shorter Likert scales, which was deemed appropriate for a single-item intended to represent an entire construct. Although there is no consensus on the optimum number of response alternatives, reliability has been shown to increase with the number of alternatives and it has been suggested that this benefit is most applicable to those concerned with the reliability of short items (Maydeu-Olivares, Kramp, García-Forero, Gallardo-Pujol, \& Coffman, 2009). From this and previous applications of single-item measures, the $1-10$ visual analogue response scale was therefore chosen over shorter Likert scales or yes/no responses.

In the case of stress, the single-item "In general, how stressful do you find your job?" with a 1 - 5 response scale from "not at all stressful" to "extremely stressful" had been used in extensive previous research on stress in the workplace (Smith et al., 2009). This provided an opportunity to examine any potential benefit of the design choices made above by providing a single-item measure that did not follow these design choices in terms of inclusion of examples and 1 - 10 response scale, while still providing a valid single-item indicator of stress based on previous research.

In total, single-item measures consisted of 25 items (see Table 2) measuring the same variables as multi-item measures achieved with 234 items. Measures were created to include individual items for each variable while trying to avoid creating an excessive number of items. For example, while reward may include esteem reward and financial reward as sub-factors, a single-item was instead used for reward as a whole. Previous research has shown that while individual elements of reward have been used it can be difficult to distinguish between them (Tsutsumi \& Kawakami, 2004) and therefore reward, as part of the effort-reward imbalance model, was measured with a single-item. Similarly, the application of coping style refers to positive coping methods (i.e. pro-active coping) and negative coping methods (i.e. emotion-focused coping) and therefore a single item was created for positive coping and a single-item for negative coping, rather than an item for each potential type of coping method. This approach to creating single-item measures for each facet of a multi-faceted construct has been recommended previously and used in areas such as personality research (Hoeppner et al., 2011). 
Table 2. Single item questions used in the present study (all from Williams, 2015).

\begin{tabular}{ll}
\hline \multicolumn{1}{c|}{ Construct } & \multicolumn{1}{c}{ Single item question } \\
\hline Work & (Effort) I feel that I do not have the time I need to get my work done (for example: I am under constant time pressure, \\
characteristics & interrupted in my work, or overwhelmed by responsibility or work demands) \\
(Reward) I feel that I have been rewarded for my efforts (for example: The respect, role, and job prospects I receive are \\
suitable for my efforts and achievements) \\
(Control) I feel that I get adequate control over my work (for example: I have a choice in what I do or how I do things, I am \\
able to learn new things, I am able to be creative) \\
(Support) I feel that I am supported by my colleagues (for example there is a good atmosphere at work, I get along with my \\
colleagues, my colleagues understand me) \\
(Bullying) I feel that I have been subjected to bullying in the workplace in the past 12 months (for example: unjustified \\
criticism, verbal/non-verbal threats, violence, humiliation or exclusion) \\
(Change) I feel that I am not consulted about changes at work (for example: There is no opportunity to question managers \\
about change, I am unclear about how change will work out in practice) \\
(Role) I feel that I don't understand my role clearly ( For example: I am not clear of what is expected of me and what tasks I \\
need to perform) \\
(Supervisor relationship) I feel that I get along well with my supervisor ( For example: I know where I stand in terms of their \\
opinion of me, my supervisor understands me, my supervisor recognizes my potential)
\end{tabular}

Individual (Positive Coping) When I find myself in stressful situations I try to deal with it in a pro-active way (For example: by taking one step differences at a time, by changing something so that it would work out, by learning from the situation, by asking someone for help) (Negative Coping) When I find myself in stressful situations I tend to look inwardly (For example: I blame myself for the situation, wish that I had the power to change what has happened, wish the situation would go away, try to forget the whole thing) (Positive attributions) The following section refers to positive experiences. In considering your responses, please try to imagine yourself experiencing a variety of positive outcomes (for example: a pay rise at work, a successful application, or a positive encounter with a friend) (Internal item) Do you believe that positive outcomes are more likely the result of external factors (e.g. luck, other's influence) or internal factors (e.g. effort, determination)

(Stable item) Do you believe that factors that currently influence positive outcomes will also be important in the future? (Global item) Do you believe that the same factors influence most positive outcomes (Negative attributions) Now please do the same for this section, but try to imagine yourself experiencing a variety of negative outcomes (for example: a meeting goes badly, a friend lets you down, you fail at a task)

Personality (Optimism) In general, I feel optimistic about the future (For example: I usually expect the best, I expect more good things to happen to me than bad, It's easy for me to relax)

(Self efficacy) I am confident in my ability to solve problems that I might face in life (For example: I can usually handle whatever comes my way, If I try hard enough I can overcome difficult problems, I can stick to my aims and accomplish my goals) (Self esteem) Overall, I feel that I have positive self-esteem (For example: On the whole I am satisfied with myself, I am able to do things as well as most other people, I feel that I am a person of worth)

(Extraversion) I consider myself to be outgoing (For example: Talkative, comfortable with myself, confident in social situations) (Agreeableness) I feel that I have an agreeable nature (For example: I feel sympathy toward people in need, I like being kind to people, I'm co-operative)

(Conscientiousness) I feel that I am a conscientious person (For example: I am always prepared, I make plans and stick to them, I pay attention to details)

(Emotional stability) I feel that I can get on well with others (For example: I'm usually relaxed around others, I tend not to get jealous, I accept people as they are)

(Openness) I feel that I am open to new ideas (For example: I enjoy philosophical discussion, I like to be imaginative, I like to be creative) (Positive affect) Thinking about myself and how I normally feel, in general, I mostly experience positive feelings (For example: I feel alert, inspired, determined, attentive)

Outcomes (Negative affect) Thinking about myself and how I normally feel, in general, I mostly experience negative feelings (For example: I feel upset, hostile, ashamed, nervous)

(Satisfaction) Overall, I feel that I am satisfied with my life (For example: In most ways my life is close to my ideal, so far I have gotten the important things I want in life)

(Depression) On a scale of one to ten, how depressed would you say you are in general? (e.g. feeling "down", no longer looking forward to things or enjoying things that you used to)

(Anxiety) On a scale of one to ten, how anxious would you say you are in general? (e.g. feeling tense or "wound up", unable to relax, feelings of worry or panic)

(Stress) In general, how stressful do you find your job 


\subsection{Analysis Procedure}

Analyses were carried out using the IBM SPSS 23 package. Guidance from Tabachnick and Fidell (2007) was followed regarding data preparation, with the data assessed for outliers, missing values, and normality. Outliers can affect the data by impacting on the distribution of variables and also therefore means, standard deviations, and the analysis of relationships with other variables. Outliers were assessed by calculating z-scores for each of the variables and using a cut-off of 3.29 as identification of a potential outlier (Tabachnick \& Fidell, 2007). Missing data were assessed in order to determine the degree and impact of missing data. The amount of missing data was assessed for each variable, with a cut-off of $10 \%$ missing data used for further investigation. Multiple imputation was chosen as the desired method for dealing with missing data. Multiple imputation is the most highly recommended approach (Tabachnick \& Fidell, 2007) and involves estimation of the missing values based on a number of regressions with associated variables using random values generated from the distribution of the missing variable.

Estimates of reliability and validity were then calculated. Construct and discriminant validity of the single-item measures was assessed using Pearson product moment correlation. A correlation of 0.50 has been previously reported as a cut-off for concurrent and discriminant validity (Van Saane et al., 2003). Reliability estimates were calculated using the Wanous et al. (1997) adjustment of the correction for attenuation formula, with a value of 0.90 as the assumed true correlation between the measures. The correction for attenuation formula is used to estimate the correlation between two variables if the two variables had perfect reliability. In correction for attenuation, the "true" correlation is calculated using the internal consistency reliabilities of the two measures and the correlation found between them. Wanous et al. (1997) have shown that if we assume the true correlation between a single- and multi-item measure of the same construct is 0.90 (a conservatively low estimate) and we know the reliability of the multi-item scale and the observed correlation between the two measures, we can use the correction for attenuation formula to estimate what the minimum reliability of the single-item measure must be for the observed correlation to occur.

Factor analyses were then carried out for the multiple-item scores and single item scores from the same group of variables (work demands; resources; personality; coping and outcomes). Regressions were then performed using factor scores to examine associations between the predictor variables and outcomes.

\section{Results}

\subsection{Concurrent and Discriminant Validity}

The average same-variable correlations for each variable group (full-scale $\mathrm{v}$ single item) were 0.66 (work characteristics), 0.63 (personality), 0.37 (coping style) and 0.63 (outcomes), suggesting good concurrent validity (above 0.50 ) in all but coping style. 


\subsection{Estimated Reliability}

The average alpha reliability of the multi-item measures was 0.81 , while the average estimated reliability (using the Wanous \& Hudy, 2001, method) of the single-item measures was 0.64 . This estimate for the single items is identical to that found by Wanous et al. (1997) for job satisfaction measures. Many of the single-item measures had comparable estimates with the alpha reliability of their multi-item counterpart (e.g. Demands 0.71 (single-item) 0.77 (multi-item) and supervisor relationship 0.92 (single-item) 0.94 (multi-item)). While a guidance coefficient alpha of 0.70 is commonly used (Nunnally, 1978) others have cited reliability estimates of 0.50 or greater as acceptable for multi-item measures in group comparisons (Van Saane et al., 2003) and these estimates are given for multi-item measures. The average estimated reliability for the single-item measures in this study was above the 0.50 level and a range of items from demands to self-esteem and positive mood were above 0.70 . The results do suggest that, where possible, multi-item measures would be more suitable for research purposes as they provide more consistently high reliability scores, however they also indicate that the estimated reliability of single-item measures is generally not prohibitively lower if practical concerns dictate their need.

\subsection{Factor Analyses}

Separate factor analyses were performed for the job characteristics, personality variables, coping scores and the outcomes. These involved principal components analyses extracting factors with Eigenvalues greater than 1 and with varimax rotation.

The analysis of the job characteristics revealed two factors:

1) Resources (41.6\% of the variance; support, control, rewards, role clarity, management of change and absence of bullying).

2) Demands (16.2\% of the variance; demands and effort).

The analysis of the personality variables also revealed a two factor solution:

1) Positive personality (34.9\% of the variance; self-esteem, optimism, self-efficacy, extraversion and emotionally stable).

2) Openness, Agreeable and Conscientious (10.7\% of the variance).

Two coping factors were identified:

1) Negative coping $(40.9 \%$ of the variance; wishful thinking, self-blame and avoidance).

2) Positive coping (21.2\% of the variance; problem focused and seek social support).

Two outcome factors were also extracted:

1) Positive well-being (55\% of the variance; happiness, satisfaction, positive affect and low depression).

2) Negative outcomes (10.9\% of the variance; stress, anxiety and negative affect).

The above factor scores were entered into two regressions, one examining 
predictors of positive outcomes, the other predictors of negative outcomes. Positive outcomes were predicted by positive personality (beta $=0.744$; s.e. $=0.096$; standardized beta $=0.731 ; \mathrm{t}=7.78 ; p<0.001 ; \mathrm{CI}=0.56-0.93)$ and positive coping (beta $=0.152$; s.e. $=0.063$; standardized beta $=0.152 ; \mathrm{t}=2.42 ; p<0.05 ; \mathrm{CI}=$ 0.03 - 0.28). Negative outcomes were predicted by job demands (beta $=0.382$; s.e. $=0.077$; standardized beta $=0.358 ; \mathrm{t}=4.97 ; p<0.001 ; \mathrm{CI}=0.23-0.53)$ and negative coping (beta $=0.299$; s.e. $=0.115$; standardized beta $=0.299 ; \mathrm{t}=2.60 ; p$ $<0.05 ; \mathrm{CI}=0.07-0.53$ ). Additional regressions included the interaction terms but these were not significant.

\section{Discussion}

Validity and reliability were explored for a newly developed range of well-being variables intended for a multi-dimensional well-being assessment tool. The descriptive statistics suggest that the range of potential scores is used, with the majority of variables ranging in score from $1-10$. Those that have shorter ranges also have shorter ranges in the multi-item scores compared to other measures. For example, agreeableness (short score 4 -10), has a counterpart minimum in the multi-item measure of 33 and mean of 58, compared to extraversion which has a minimum 17 and mean 43. Mean scores in the single-item measures also vary from 3.4 (negative mood) to 8.2 (agreeableness). The descriptive statistics therefore provide an initial indication that the single-item measures represent the valid range of scores in the respondents.

The work characteristics items showed generally good validity, with all but two of the items having a correlation with their multi-item counterpart that was greater than 0.60 . What these results therefore indicate is that the single-item measures of work characteristics provide valid scores in the majority of cases. However the relationship between some closely associated constructs, such as demands and effort, may be highlighted in single-item measures of these constructs. The implication of this is that the single-item measures may not represent the distinction between these associated constructs as well as multi-item measures. A study of the unique variance represented by these items in well-being outcomes will establish further whether these items are complimentary or the inclusion of both is redundant.

The personality items also provided promising results for single-item use. Correlations for extraversion (0.80), self-esteem (0.76), and optimism (0.75) demonstrated that scores on single-item personality measures can provide very high correlations with scores on multi-item measures. Self-esteem and optimism had strong correlations with their multi-item counterpart at 0.76 and 0.75 respectively. The results for these variables are similar to those for work characteristics, with generally good validity and some strong correlations between single- and multi-item measures of the same constructs. However, as with work characteristics, the single-item measures may not identify unique variance in closely associated constructs such as self-efficacy and optimism and this should 
be studied further.

The coping single-item measures were designed to assess positive or pro-active coping style and negative or emotional coping. These were then compared to the more specific styles of problem focused and seeks social support variables (positive coping) and blame self, wishful thinking, and avoidance variables (negative coping), as well as the combined group scores of these variables. The coping measures provided less valid results than work characteristics or personality groups, although both positive and negative coping were significant predictors of outcomes.

The outcome measures show good concurrent validity, with single-multi item correlations all greater than 0.60 . The presence of separate factors for positive well-being and negative outcomes shows that it is important to measure both rather than trying to infer one from the other.

Overall many of the findings of this study were promising and demonstrated the ability for single-item measures to provide valid scores on a multitude of variables associated with well-being. The inclusion of individual effects (personality and coping) also greatly added to the predictive power of the sample. Indeed, many of the occupational factors, especially resources, had no significant association with outcomes. The distinction between predictors of positive and negative outcomes was clear and again supports the necessity of investigating both types rather than inferring one from another.

A larger sample would provide more generalizable results, however confidence in the results can be maintained by comparison with other studies, with many of the current findings being in line with previous research on the same variables. A limitation related to the sample is, however, that they represent largely well educated, working adults from a university environment. This may provide results which represent those who have a good understanding of the constructs involved and an ability to make a good judgment of the concept the single-item measure is referring to. It may therefore be that those who are less well educated or familiar with the constructs involved may produce poorer representations using the single item measures. The make-up of the sample also means that the items may be less representative of those who may score at the extreme ends of the variables.

Another potential limitation is having the multi-item measures and single-item measures in the same questionnaire, as each item may influence the score on the other. Similarly, measures of associated variables such as demands and effort may also influence each other. The questionnaire was designed to limit this by not putting the related single- and multi-item measures next to each other and by presenting all the multi-item measures after all the single-item measures had been completed. Both these choices created temporal distance between the items, however, some memory effect cannot be ruled out.

Another limitation is that the study involved a broad range of measures and ideally a more focused study or series of studies would have provided a more desirable approach to researching these variables. This would represent a more 
in-depth approach that would start with few variables and build up in terms of breadth, providing more comprehensive study of specific measures at each stage of the process. However, the chosen approach of starting with a broad range of variables and potentially reducing down by removing the poorly performing items was determined to be more appropriate to the project as it would be more practical in terms of the resources and time constraints of the project, better represent the already established multi-dimensional nature of well-being, examine the relative importance of variables that have potential to be redundant alongside each other, and establish the most significant variables in the process. The limitation of this is that weaker variables or more complex relationships that may be appropriate for applications not primarily concerned with practicality are less well represented and that the potential impact of error and inflation is increased.

An alternative approach could also have been taken regarding the development of the single-item measures, which may have provided better results. In the design of the single-item measures the example items taken from the multi-item measures were done so to provide a representation of the breadth of the items in the multi-item measure. An alternative approach would have been to initially use factor analysis on the multi-item measure to choose examples with the strongest loading. This method may have provided better results as the inclusion of items with poorer loading on the factor would be more likely to lead respondents away from the construct. It is also possible however that the highest loading items would be most likely to be so closely related as to reduce the benefit of including example items in the single-item measure. Additionally, if a multi-item measure is properly developed and validated then every item should load strongly on the factor. The factor analysis approach does, however, provide a possible approach to improving the validity of single-item measures that may be explored in future research.

Finally, the single-item measures are compared to only one multi-item comparison with its own error in measurement and therefore the conclusion on how well the single item measure represents each construct is limited by the ability for the multi-item measure to do so. It is not conclusive therefore how well the single-item measure really represents each construct. The multi-item measures, however, do accurately represent how these constructs would normally be measured in practice and therefore the results are relevant in terms of how valid and reliable the single-item measures are as alternatives to these. This is in line with the intention of the measures-to provide a practical alternative with acceptable comparative performance.

\section{Conclusion}

In summary, the results from this study demonstrate the value of using an adapted DRIVE model to examine both positive well-being and negative outcomes such as stress and anxiety. In addition, the use of single items (the WPQ) 
to measure components of the model has been validated by comparison with longer scales measuring the same concepts. The items from the WPQ loaded on the same factors as the longer items and analysis of the factor scores showed that positive well-being was predicted by positive personality and by positive coping. In contrast, negative outcomes, such as stress and anxiety, were predicted by job demands and negative coping. These results extend previous research by considering a wider range of predictors and by examining both positive and negative outcomes. Although this study was largely aimed at testing a theoretical model and applying a new measuring instrument, it has large practical implications. The WPQ can now be used in longitudinal studies and in interventions which require a rapid evaluation. This will help prevention and management of stress in university staff and will also lead to promotion of positive wellbeing.

\section{References}

Abouserie, R. (1996). Stress, Coping, Strategies and Job Satisfaction in University Academic Staff. Educational Psychology, 16, 49-56.

https://doi.org/10.1080/0144341960160104

Bandura, A. (1988). Self-Efficacy Conception of Anxiety. Anxiety Research, 1, 77-98. https://doi.org/10.1080/10615808808248222

Bentley, P. J., Coates, H., Dobson, I. R., Goedegebuure, L., \& Meek, V. L. (2013). Factors Associated with Job Satisfaction amongst Australian University Academics and Future Workforce Implications. In Job Satisfaction around the Academic World (pp. 29-53). Dordrecht: Springer. https://doi.org/10.1007/978-94-007-5434-8_3

Black, C. M. (2008). Working for a Healthier Tomorrow: Dame Carol Black's Review of the Health of Britain's Working Age Population. The Stationery Office.

Blix, A. G., Cruise, R. J., Mitchell, B. M., \& Blix, G. G. (1994). Occupational Stress among University Teachers. Educational Research, 36, 157-169. https://doi.org/10.1080/0013188940360205

Chang, Y., Wang, P. C., Li, H. H., \& Liu, Y. C. (2011). Relations among Depression, Self-Efficacy and Optimism in a Sample of Nurses in Taiwan. Journal of nursing management, 19, 769-776. https://doi.org/10.1111/j.1365-2834.2010.01180.x

Cohen, S., \& Williamson, G. (1988). Perceived Stress in a Probability Sample of the United States. In S. Spacapan, \& S. Oskamp (Eds.), The Social Psychology of Health: Claremont Symposium on Applied Social Psychology (pp. 31-67). Newbury Park, CA: Sage.

Costa, P. T., \& McCrae, R. R. (1980). Influence of Extraversion and Neuroticism on Subjective Well-Being: Happy and Unhappy People. Journal of Personality and Social Psychology, 38, 668-678. https://doi.org/10.1037/0022-3514.38.4.668

DeNeve, K. M., \& Cooper, H. (1998). The Happy Personality: A Meta-Analysis of 137 Personality Traits and Subjective Well-Being. Psychological Bulletin, 124, 197-229. https://doi.org/10.1037/0033-2909.124.2.197

Diener, E. (1984). Subjective Well-Being. Psychological Bulletin, 95, 542-575. https://doi.org/10.1037/0033-2909.95.3.542

Diener, E. (2000). Subjective Well-Being: The Science of Happiness and a Proposal for a National Index. American Psychologist, 55, 34-43.

https://doi.org/10.1037/0003-066X.55.1.34 
Diener, E., Emmons, R. A., Larsen, R. J., \& Griffin, S. (1985). The Satisfaction with Life Scale. Journal of Personality Assessment, 49, 71-75.

Diener, E., Oishi, S., \& Lucas, R. E. (2003). Personality, Culture, and Subjective Well-Being: Emotional and Cognitive Evaluations of Life. Annual Review of Psychology, 54, 403-425. https://doi.org/10.1146/annurev.psych.54.101601.145056

Diener, E., Sapyta, J. J., \& Suh, E. (1998). Subjective Well-Being Is Essential to Well-Being. Psychological Inquiry, 9, 33-37. https://doi.org/10.1146/annurev.psych.54.101601.145056

Diener, E., Suh, E. M., Lucas, R. E., \& Smith, H. L. (1999). Subjective Well-Being: Three Decades of Progress. Psychological Bulletin, 125, 276-302. https://doi.org/10.1037/0033-2909.125.2.276

Dolan, P., Peasgood, T., \& White, M. (2008). Do We Really Know What Makes Us Happy? A Review of the Economic Literature on the Factors Associated with Subjective Well-Being. Journal of Economic Psychology, 29, 94-122. https://doi.org/10.1016/j.joep.2007.09.001

Fisher, S. (1994). Stress in Academic Life: The Mental Assembly Line. Buckingham: Open University Press.

Folkman, S., \& Lazarus, R. S. (1980). An Analysis of Coping in a Middle-Aged Community Sample. Journal of Health and Social Behavior, 21, 219-239. https://doi.org/10.2307/2136617

Gargiulo, R. A., \& Stokes, M. A. (2009). Subjective Wellbeing as an Indicator for Clinical Depression. Social Indicators Research, 92, 517-527.

Gillespie, N. A., Walsh, M., Winefield, A. H., Dua, J., \& Stough, C. (2001). Occupational Stress in Universities: Staff Perceptions of the Causes, Consequences and Moderators of Stress. Work \& Stress, 15, 53-72. https://doi.org/10.1080/02678370117944

Hayes, N., \& Joseph, S. (2003). Big 5 Correlates of Three Measures of Subjective Well-Being. Personality and Individual Differences, 34, 723-727. https://doi.org/10.1016/S0191-8869(02)00057-0

Headey, B., \& Wearing, A. (1989). Personality, Life Events, and Subjective Well-Being: toward a Dynamic Equilibrium Model. Journal of Personality and Social Psychology, 57, 731-739. https://doi.org/10.1037/0022-3514.57.4.731

Hoeppner, B. B., Kelly, J. F., Urbanoski, K. A., \& Slaymaker, V. (2011). Comparative utility of a Single-Item versus Multiple-Item Measure of Self-Efficacy in Predicting Relapse among Young Adults. Journal of Substance Abuse Treatment, 41, 305-312.

HSE (2004). Management Standards. http://www.hse.gov.uk/stress/standards/

HSE (2013). Stress and Psychological Disorders in Great Britain 2013. http://www.hse.gov.uk/statistics/causdis/stress/stress.pdf

Johnson, J. V., \& Hall, E. M. (1988). Job Strain, Work Place Social Support, and Cardiovascular Disease: A Cross-Sectional Study of a Random Sample of the Swedish Working Population. American Journal of Public Health, 78, 1336-1342. https://doi.org/10.2105/AJPH.78.10.1336

Judge, T. A., Erez, A., Bono, J. E., \& Thoresen, C. J. (2002). Are Measures of Self-Esteem, Neuroticism, Locus of Control, and Generalized Self-Efficacy Indicators of a Common Core Construct? Journal of Personality and Social Psychology, 83, 693-710. https://doi.org/10.1037/0022-3514.83.3.693

Keyes, C. (2006). Subjective Well-Being in Mental Health and Human Development Research Worldwide: An Introduction. Social Indicators Research, 77, 1-10. https://doi.org/10.1007/s11205-005-5550-3 
Kinman, G. (2001). Pressure Points: Review of Research on Stressors and Strains in UK Academics. Educational Psychology, 21, 473-492. https://doi.org/10.1080/01443410120090849

Kinman, G. (2008). Work Stressors, Health and Sense of Coherence in UK Academic Employees. Educational Psychology, 28, 823-835. https://doi.org/10.1080/01443410802366298

Kinman, G., \& Court, S. (2010). Psychosocial Hazards in UK Universities: Adopting a Risk Assessment Approach. Higher Education Quarterly, 64, 413-428. https://doi.org/10.1111/j.1468-2273.2009.00447.x

Kluemper, D. H., Little, L. M., \& DeGroot, T. (2009). State or Trait: Effects of State Optimism on Job-Related Outcomes. Journal of Organizational Behavior, 30, 209-231. https://doi.org/10.1002/job.591

Knapp, M., McDaid, D., Mossialos, E., \& Thornicroft, G. (2006). Mental Health Policy and Practice across Europe. Maidenhead: Open University Press.

Larsen, R. J., Diener, E., \& Emmons, R. A. (1985). An Evaluation of Subjective Well-Being Measures. Social Indicators Research, 17, 1-17.

Lease, S. H. (1999). Occupational Role Stressors, Coping, Support, and Hardiness as Predictors of Strain in Academic Faculty: An Emphasis on New and Female Faculty. Research in Higher Education, 40, 285-307.

Lee-Flynn, S. C., Pomaki, G., DeLongis, A., Biesanz, J. C., \& Puterman, E. (2011). Daily Cognitive Appraisals, Daily Affect, and Long-Term Depressive Symptoms: The Role of Self-Esteem and Self-Concept Clarity in the Stress Process. Personality and Social Psychology Bulletin, 37, 255-268. https://doi.org/10.1177/0146167210394204

Maciejewski, P. K., Prigerson, H. G., \& Mazure, C. M. (2000). Self-Efficacy as a Mediator between Stressful Life Events and Depressive Symptoms. Differences Based on History of Prior Depression. British Journal of Psychiatry, 176, 373-378. https://doi.org/10.1192/bjp.176.4.373

Mark, G. M., \& Smith, A. P. (2008). Stress Models: A Review and Suggested New Direction. In J. Houdmont, \& S. Leka (Eds.), Occupational Health Psychology, European Perspectives on Research, Education and Practice (Vol. 3, pp. 111-144). Nottingham: Nottingham University Press.

Mark, G., \& Smith, A. P. (2012a). Effects of Occupational Stress, Job Characteristics, Coping, and Attributional Style on the Mental Health and Job Satisfaction of University Employees. Anxiety, Stress \& Coping, 25, 63-78. https://doi.org/10.1080/10615806.2010.548088

Mark, G., \& Smith, A. P. (2012b). Occupational Stress, Job Characteristics, Coping, and the Mental Health of Nurses. British Journal of Health Psychology, 17, 505-521. https://doi.org/10.1111/j.2044-8287.2011.02051.x

Maydeu-Olivares, A., Kramp, U., García-Forero, C., Gallardo-Pujol, D., \& Coffman, D. (2009). The Effect of Varying the Number of Response Alternatives in Rating Scales: Experimental Evidence from Intra-Individual Effects. Behavior Research Methods, 41, 295-308. https://doi.org/10.3758/BRM.41.2.295

Nunnally, J. C. (1978). Psychometric Theory (2nd ed.). London: McGraw-Hill.

Parkinson, J. (2007). Review of Scales of Positive Mental Health Validated for Use with Adults in the UK: Technical Report. Edinburgh: Health Scotland.

Pavot, W., \& Diener, E. (1993). The Affective and Cognitive Context of Self-Reported Measures of Subjective Well-Being. Social Indicators Research, 28, 1-20. https://doi.org/10.1007/BF01086714 
Peterson, C. (1991). On Shortening the Expanded Attributional Style Questionnaire. Journal of Personality Assessment, 56, 179-183. https://doi.org/10.1207/s15327752jpa5601_16

Quine, L. (1999). Workplace Bullying in NHS Community Trust: Staff Questionnaire Survey. British Medical Journal, 318, 228-232. https://doi.org/10.1136/bmj.318.7178.228

Rick, J., Briner, R. B., Daniels, K., Perryman, S., \& Guppy, A. (2001). A Critical Review of Psychosocial Hazard Measures. Norwich: HSE Books, HMSO.

Rosenberg, M. (1965). Society and the Adolescent Self-Image. Princeton, NJ: Princeton University Press.

Sackett, P. R., \& Larson Jr., J. R. (1990). Research Strategies and Tactics in Industrial and Organizational Psychology. In M. D. Dunnett, \& L. M. Hough (Eds.), Handbook of Industrial and Organizational Psychology (2nd ed., Vol. 1, pp. 419-489). Palo Alto, CA: Consulting Psychologists Press.

Sanne, B., Torp, S., Mykletun, A., \& Dahl, A. A. (2005). The Swedish Demand-Control-Support Questionnaire (DCSQ): Factor Structure, Item Analyses, and Internal Consistency in a Large Population. Scandinavian Journal of Public Health, 33, 166-174. https://doi.org/10.1080/14034940410019217

Saucier, G. (1994). Mini-Markers: A Brief Version of Goldberg's Unipolar Big-Five Markers. Journal of Personality Assessment, 63, 506-516.

https://doi.org/10.1207/s15327752jpa6303_8

Scandura, T. A., \& Graen, G. B. (1984). Moderating Effects of Initial Leader-Member Exchange Status on the Effects of a Leadership Intervention. Journal of Applied Psychology, 69, 428-436. https://doi.org/10.1037/0021-9010.69.3.428

Scheier, M. F., Carver, C. S., \& Bridges, M. W. (1994). Distinguishing Optimism from Neuroticism (and Trait Anxiety, Self-Mastery, and Self-Esteem): A Reevaluation of the Life Orientation Test. Journal of Personality and Social Psychology, 67, 1063-1078. https://doi.org/10.1037/0022-3514.67.6.1063

Schimmack, U., Oishi, S., Furr, R. M., \& Funder, D. C. (2004). Personality and Life Satisfaction: A Facet-Level Analysis. Personality and Social Psychology Bulletin, 30, 1062-1075.

Schwarzer, R., \& Hallum, S. (2008). Perceived Teacher Self-Efficacy as a Predictor of Job Stress and Burnout: Mediation Analyses. Applied Psychology, 57, 152-171. https://doi.org/10.1111/j.1464-0597.2008.00359.x

Schwarzer, R., \& Jerusalem, M. (1995). Generalized Self-Efficacy Scale. In J. Weinman, S. Wright, \& M. Johnston (Eds.), Measures in Health Psychology: A User's Portfolio. Causal and Control Beliefs (pp. 35-37). Windsor: NFER-NELSON.

Sharpe, J. P., Martin, N. R., \& Roth, K. A. (2011). Optimism and the Big Five Factors of Personality: Beyond Neuroticism and Extraversion. Personality and Individual Differences, 51, 946-951. https://doi.org/10.1016/j.paid.2011.07.033

Sharpley, C. F., Reynolds, R., Acosta, A., \& Dua, J. K. (1996). The Presence, Nature and Effects of Job Stress on Physical and Psychological Health at a Large Australian University. Journal of Educational Administration, 34, 73-86. https://doi.org/10.1108/09578239610128630

Siegrist, J. (1996). Adverse Health Effects of High-Effort/Low-Reward Conditions. Journal of Occupational Health Psychology, 1, 27-41. https://doi.org/10.1037/1076-8998.1.1.27

Siegrist, J., Starke, D., Chandola, T., Godin, I., Marmot, M., Niedhammer, I. et al. (2004). 
The Measurement of Effort-Reward Imbalance at Work: European Comparisons. Social Science and Medicine, 58, 1483-1499. https://doi.org/10.1016/S0277-9536(03)00351-4

Singh, S. N., \& Bush, R. F. (1998). Research Burnout in Tenured Marketing Professors: An Empirical Investigation. Journal of Marketing Education, 20, 4-15. https://doi.org/10.1177/027347539802000102

Smith, A. P., McNamara, R. L., \& Wellens, B. T. (2004). Combined Effects of Occupational Health Hazards: HSE Books.

Smith, A., Johal, S., \& Wadsworth, E. (2000). The Scale of Occupational Stress: The Bristol Stress and Health at Work Study: HSE Books Sudbury.

Smith, A., Wadsworth, E., Chaplin, K., Allen, P., \& Mark, G. (2009). What Is a Good Job? The Relationship between Work/Working and Improved Health and Well-Being. Wigston: IOSH.

Steel, P., Schmidt, J., \& Shultz, J. (2008). Refining the Relationship between Personality and Subjective Well-Being. Psychological Bulletin, 134, 138-161.

https://doi.org/10.1037/0033-2909.134.1.138

Tabachnick, B. G., \& Fidell, L. S. (2007). Using Multivariate Statistics (5th ed.). Boston, MA: Pearson Education, Inc.

Thompson, E. R. (2007). Development and Validation of an Internationally Reliable Short-Form of the Positive and Negative Affect Schedule (PANAS). Journal of Cross-Cultural Psychology, 38, 227-242. https://doi.org/10.1177/0022022106297301

Tsutsumi, A., \& Kawakami, N. (2004). A Review of Empirical Studies on the Model of Effort-Reward Imbalance at Work: Reducing Occupational Stress by Implementing a New Theory. Social Science \& Medicine, 59, 2335-2359. https://doi.org/10.1016/j.socscimed.2004.03.030

Tytherleigh, M. Y., Webb. C., Cooper, C. L., \& Ricketts, C. (2005). Occupational Stress in UK Higher Education Institutions: A Comparative Study of All Staff Categories. Higher Education Research \& Development, 24, 41-61. https://doi.org/10.1080/0729436052000318569

Tytherleigh, M.Y, Jacobs, P.A., Webb, C., \& Ricketts, C. (2007). Gender, Health and Stress in English University Staff-Exposure or Vulnerability? Applied Psychology: An International Review, 56, 267-287.

Van Der Doef, M., \& Maes, S. (1999). The Job Demand-Control (-Support) Model and Psychological Well-Being: A Review of 20 Years of Empirical Research. Work and Stress, 13, 87-114. https://doi.org/10.1080/026783799296084

Van Saane, N., Sluiter, J., Verbeek, J., \& Frings-Dresen, M. (2003). Reliability and Validity of Instruments Measuring Job Satisfaction-A Systematic Review. Occupational Medicine, 53, 191-200.

Vitaliano, P. P., Russo, J., Carr, J. E., Maiuro, R. D., \& Becker, J. (1985). The Ways of Coping Checklist: Revision and Psychometric Properties. Multivariate Behavioural Research, 20, 3-26. https://doi.org/10.1207/s15327906mbr2001_1

Waldron, S. (2010). Measuring Subjective Wellbeing in the UK. Newport: Office for National Statistics.

Wanous, J. P., \& Hudy, M. J. (2001). Single-Item Reliability: A Replication and Extension. Organizational Research Methods, 4, 361-375. https://doi.org/10.1177/109442810144003

Wanous, J. P., Reichers, A. E., \& Hudy, M. J. (1997). Overall Job Satisfaction: How Good Are Single-Item Measures? Journal of Applied Psychology, 82, 247-251. 
https://doi.org/10.1037/0021-9010.82.2.247

Williams G. M. (2015) Researching and Developing Mental Health and Wellbeing Assessment Tools for Supporting Employees and Employers in Wales. http://orca.cf.ac.uk/71443/1/2015williamsphd.pdf

Williams, G. M., \& Smith, A. P. (2012). A Holistic Approach to Stress and Well-Being. Part 6: The Wellbeing Process Questionnaire (WPQ Short Form). Occupational Health (At Work), 9, 29-31.

Winefield, A. H., \& Jarrett, R. (2001). Occupational Stress in University Staff. International Journal of Stress Management, 8, 285-298. https://doi.org/10.1023/A:1017513615819

Winefield, H. R., Boyd, C., \& Winefield, A. H. (2014). Work-Family Conflict and Well-Being in University Employees. The Journal of Psychology, 148, 683-697. https://doi.org/10.1080/00223980.2013.822343

Wismar, M., McKee, M., Ernst, K., Srivastava, D., \& Busse, R. (2013). Measurement of and Target-Setting for Well-Being: An Initiative by the WHO Regional Office for Europe/Second Meeting of the Expert Group, Paris, France, 25-26 June 2012.

Zigmond, A. S., \& Snaith, R. P. (1983). The Hospital Anxiety and Depression Scale. Acta Psychiatrica Scandinavica, 67, 361-370.

https://doi.org/10.1111/j.1600-0447.1983.tb09716.x 